Volume XII, No. 1, pp. 483488, 2011

\title{
ANALYZING THE ROLE OF SOME PERSONAL DETERMINANTS IN WEB 2.0 APPLICATIONS USAGE
}

\author{
Adel M. Aladwani, Kuwait University, adel.aladwani@ku.edu.kw
}

\begin{abstract}
This study examines the personal determinants of Web 2.0 applications usage in Kuwait. The analyses revealed that: (1) Web 2.0 attitudes had a significant, positive influence on all dimensions of Web 2.0 usage but one, variety of use, (2) there were no differences between males and females in terms of Web 2.0 attitudes, duration of use, and frequency of use but females used more Web 2.0 applications than males do, (3) there were no age or training effects along all usage variables (i.e., duration of use, frequency of use, and variety of use), and (4) age and personal training significantly affected Web 2.0 attitudes. I discuss the implications of these findings.
\end{abstract}

Keywords: Web 2.0, Social Networking Sites, Technology Acceptance, Attitudes, Personal Determinants.

\section{INTRODUCTION}

A quick look at the diffusion statistics of Web 2.0 applications among individuals in the different countries of the world (InternetWorldStats.com/Facebook.htm) reveals at least one interesting pattern. Despite the fact that individuals' use of Web 2.0 applications is quickly spreading in many countries, individuals' usage of Web 2.0 in many other countries is still lagging behind. These mixed results give rise to an important question: what are the personal factors determining the acceptance of Web 2.0 by individual users? This study tries to address this question.

Examining the variables facilitating or impeding users' acceptance of a new information technology is a significant theme of research in the information systems field [see for example, 22]. Numerous attempts have been made to study individuals' acceptance of many types of technologies and applications such as personal computers, laptops, the Internet, e-mail technology, and e-Commerce websites, to name a few $[1,4,5,9,11,14,17]$. So far, however, scanty attention has been paid to study personal determinants of Web 2.0 usage. This is unfortunate because in order to serve Web 2.0 customers adequately, developers of these tools have to understand the needs and preferences of the different user groups.

The goal of this paper is to shed the light on personal determinants of Web 2.0 applications acceptance. More specifically, the author will examine the patterns of Web 2.0 usage by individual users (as defined by usage variety, duration, and frequency) and their relationship with attitudes toward Web 2.0, and certain of personal (e.g., age, gender, and personal training) determinants of Web 2.0 applications acceptance.

The rest of this manuscript is divided as follows. Next, I explicate the research model of the study depicting personal factors influencing Web 2.0 applications usage. Then, I describe the methodology used in this study along with results of scales' validation. Third, I present hypotheses-testing results; and in the last section I discuss the research and practical implications of the findings.

\section{RESEARCH MODEL}

In the past three decades, the concept of information technology acceptance has received much attention from information systems scholars around the world. In this research stream, the study of attitudes toward technology applications has played a central role in explaining their acceptance by individuals [7,11]. Additionally, several researchers have suggested that individual variables are critical correlates of people's attitudes toward and usage of information technology applications and Internet applications. In particular, the seminal papers of Dickson, Senn, and Chervany [13] and Zmud [27] clearly suggest that personal variables such as age, gender, and personal training can discriminate between users and non-users of information technology. 
Volume XII, No. 1, pp. 483488, 2011

The proposed research model of this investigation theorizes that age, gender, and personal training can influence beliefs about Web 2.0 usage, which in turn can influence actual Web 2.0 acceptance. The support for including the aforementioned variables in the model will be provided next.

As mentioned before, little, if any, research explored the personal factors determining Web 2.0 applications acceptance by individuals. However, past research provides some insights relevant to the influence of these factors in the context of traditional information technologies. In fact, some scholars argued that personal factors are central to understanding individual-level technology acceptance decisions [26]. Furthermore, the general evidence coming from the technology acceptance research (like Technology Acceptance Model studies) supports the conclusion that if managers want to influence technology acceptance, then they must influence users' beliefs toward the same [22]. For example, Davis [11] highlighted the importance of users' beliefs about an information technology application (as measured by usefulness and easiness) for its acceptance.

Moreover, some scholars have asserted that personal variables such as age, gender, and training are important predictors of beliefs about and usage of information technologies and applications in general. For example, Aladwani [2] found that age is negatively related to anxiety beliefs, the time and frequency of using the technology. Guimaraes and Igbaria [16] reported a significant relationship between gender and beliefs about technology usage. Gefen and Straub [14] found that gender has influence on attitudes toward and use of e-mail systems. Aladwani [2] found that training reduces computer anxiety and enhances variety of use. In the context of Web 2.0 technologies, Pfeil, Arjan, and Zaphiris [24] found many differences between young and old users of the social networking website MySpace including in terms of variety of use. Magnuson, Dundes, and Dundes [23] found gender disparities in the way MySpace profiles are presented. The authors found that young people make more use of different media within MySpace. Although the link between personal training and Web tools acceptance have not been addressed adequately by the literature, the absence of training have been found to be a critical barrier to the success of new technologies in general [25]. Thus, I hypothesize that:

H1: Attitudes toward using Web 2.0 applications will significantly influence Web 2.0 usage variety, duration, and frequency.

H2a: $\quad$ Age will significantly influence attitudes toward using Web 2.0.

H2b: Age will significantly influence Web 2.0 applications usage variety, duration, and frequency.

H3a: Gender will significantly influence attitudes toward using Web 2.0.

H3b: Gender will significantly influence Web 2.0 applications usage variety, duration, and frequency.

H4a: $\quad$ Personal training will significantly influence attitudes toward using Web 2.0.

H4b: Personal training will significantly influence Web 2.0 applications usage variety, duration, and frequency.

\section{Sample}

\section{METHODOLOGY}

Because there is no sampling frames for Web 2.0 applications users in Kuwait, we used a convenience sampling procedure to gather data for our study. The research assistants distributed questionnaires to a convenience sample of ninety-five Web 2.0 users from the professional staff working for eight private and public organizations located in the State of Kuwait. The drop-off/pick-up method of questionnaire administration was used. Of the ninety-five questionnaires distributed, eighty-six usable questionnaires were picked-up (approximately a ninety-one percent response rate).

Of the eighty-six one responding Web 2.0 users, fifty-five are males and thirty-one are females. The average age of the respondents is approximately thirty years and the standard deviation is approximately eight years. Forty-one users are from the public relations and media areas, twenty-nine users work in the healthcare industry, and sixteen users are work in marketing and financial services. 
Volume XII, No. 1, pp. 483-488, 2011

\section{Operational Measures}

Based on the works of past research $[2,8,12,20,21]$, the author employed three indicators to tap Web 2.0 applications usage: frequency of use, duration of use, and variety of use. Frequency of use was measured on a single six-point scale: (1) "once a week", (2) "less than once in a given working day", (3) "once in a given working day", (4) "about once an hour", (5) "a few times an hour", (6) "many times an hour". Duration of use was measured on a single sixpoint scale: (1) "almost never", (2) "less than $1 \frac{1}{2}$ hour a day", (3) "from $1 \frac{1}{2}$ hour to 1 hour a day", (4) "1-2 hours a day", (5) "2-3 hours a day", (6) "more than 3 hours a day". Finally, a list of nine Web 2.0 applications (e.g., Twitter, Facebook, LinkedIn, Google Docs, YouTube, Wikipedia, Blogger, iTunes, and Yahoo Answers) was given to the respondents to indicate whether they used Web 2.0 to perform these tasks. I adopted a use/no-use format for the purpose of the analysis. I then summed the answers to the ten items to come up with an indicator for the last Web 2.0 usage measure, variety of use.

The attitudes scale taps user's beliefs about using Web 2.0 applications in accomplishing job-related tasks $[2,6,8,10,15,18]$. The instrument consists of four items. Sample items included are: "Using Web 2.0 applications improves my productivity on the job" and "Using Web 2.0 applications allows me to access, store, and retrieve work information easily without difficulties." A likert-type response format was provided with five anchors: (1) "strongly disagree", (2) "disagree", (3) "neutral", (4) "agree", and (5) "strongly agree". A principal component factor analysis (with varimax rotation) of the four items produced one factor that explained most of the common variance. Cronbach's alpha for the four-item scale was .86.

The predictor variables in this study include age, gender, training, and beliefs about Web 2.0. Single item questions were used to ascertain participants' age, gender, and training .Gender of respondents was coded (0) for men and (1) for women. The respondents were asked to indicate the extent of Web 2.0 self-training they had undergone using a five point scale: (1) "no training" (2) "some training", (3) "regular training", (4) "extended training", and (5) "very extensive training".

\section{DATA ANALYSES \& RESULTS}

The author used regression analysis to test the proposed seven (7) relationships. For the purpose of determining the strength and direction of relationships in the theorized model, standardized betas may be used. The model in this study postulates that age, gender, and training can influence attitudes toward Web 2.0, which in turn can influence Web 2.0 usage. Table 1 reports descriptive statistics and cross-correlations matrix of the variables comprising the research model.

Table 1: Descriptive Statistics and Cross-correlations

\begin{tabular}{|l|c|c|c|c|c|c|c|c|}
\hline & Mean & SD & 1 & 2 & 3 & 4 & 5 & 6 \\
\hline 1 & 29.51 & 8.11 & 1 & & & & & \\
\hline 2 & .36 & .48 & $-.21 \mathrm{a}$ & 1 & & & & \\
\hline 3 & 3.72 & .98 & -.20 & .09 & 1 & & & \\
\hline 4 & 3.77 & 1.02 & $-.31 \mathrm{~b}$ & .06 & $.40 \mathrm{~b}$ & 1 & & \\
\hline 5 & 4.02 & 1.72 & -.10 & .19 & .16 & $.58 \mathrm{~b}$ & 1 & \\
\hline 6 & 3.93 & 1.72 & $-.27 \mathrm{a}$ & .06 & $.32 \mathrm{~b}$ & $.55 \mathrm{~b}$ & $.51 \mathrm{~b}$ & 1 \\
\hline 7 & 4.65 & 2.00 & .12 & $-.43 \mathrm{~b}$ & -.15 & $-.10 \mathrm{~b}$ & -.12 & -.04 \\
\hline
\end{tabular}

1. AGE, 2. GENDER, 3. PERSONAL TRAINING, 4. ATTITUDE, 5. Frequency, 6. Duration, 7. Variety

The regression analysis results summarized in Table 2 show that age $(\beta=-.24, \mathrm{p}<.05)$, and personal training $(\beta=$ $.36, \mathrm{p}<.01)$ are significant correlates of attitudes toward Web 2.0 technologies. The findings also show that gender does predict Web 2.0 attitudes. Table 3 indicates that only attitudes toward Web 2.0 significantly predicts frequency 
Volume XII, No. 1, pp. 483488, 2011

of use $(\beta=.58, \mathrm{p}<.01)$ and duration of use $(\beta=.55, \mathrm{p}<.01)$. The table also shows that gender significantly predicts variety of use $(\beta=-.43, \mathrm{p}<.01)$.

Table 2: The Web 2.0 Attitudes Model

\begin{tabular}{|l|l|l|}
\hline & Beta & $\mathrm{T}$ \\
\hline Age & $-.244 \mathrm{a}$ & -2.46 \\
\hline Gender & -.029 & -.29 \\
\hline Personal Training & $.356 \mathrm{~b}$ & 3.58 \\
\hline \multicolumn{2}{|c|}{$\mathrm{a}=\mathrm{p}<.05, \mathrm{~b}=\mathrm{p}<.01$}
\end{tabular}

Table 3: Beta Scores for the Three Web 2.0 Usage Models

\begin{tabular}{|l|c|c|c|}
\hline & Frequency & Duration & Variety \\
\hline Age & .09 & -.12 & .03 \\
\hline Gender & .16 & -.03 & $-.43 \mathrm{~b}$ \\
\hline Personal Training & -.08 & .11 & -.11 \\
\hline Attitude & $.58 \mathrm{~b}$ & $.55 \mathrm{a}$ & -.08 \\
\hline \multicolumn{4}{|c|}{$\mathrm{a}=\mathrm{p}<.05, \mathrm{~b}=\mathrm{p}<.01$} \\
\end{tabular}

The above mixed findings suggest that personal variables in the model influence Web 2.0 applications usage indirectly through Web 2.0 attitudes. Notwithstanding, the negative impact of gender $(0=$ male and $1=$ female $)$ on variety of use is interesting and it indicates that male users utilize more Web tools (Mean=5.29, $\mathrm{SD}=1.81$ ) than female users $(\mathrm{M}=3.52, \mathrm{SD}=1.82)$. Table 4 shows ANOVA results of variety of use by gender. It reveals that male and female participants differ in almost all nine Web 2.0 applications usage patterns but two, YouTube and LinkedIn. Male users exhibit a higher mean usage score than female users in all Web 2.0 applications except in the case of YouTube.

Table 4: ANOVA (Variety of Use by Gender)

\begin{tabular}{|l|l|l|}
\hline & \multicolumn{1}{|c|}{ F } & \multicolumn{1}{c|}{ Sig. } \\
\hline Twitter & 18.69 & $\mathbf{. 0 0 0}$ \\
\hline Facebook & 12.92 & $\mathbf{. 0 0 1}$ \\
\hline Google Docs & 8.11 & $\mathbf{. 0 0 6}$ \\
\hline YouTube & 1.75 & .189 \\
\hline Yahoo Answers & 12.44 & $\mathbf{. 0 0 1}$ \\
\hline LinkedIn & .58 & .447 \\
\hline Wikipedia & 12.71 & $\mathbf{. 0 0 1}$ \\
\hline iTunes & 8.11 & $\mathbf{. 0 0 6}$ \\
\hline Blogger & 5.59 & $\mathbf{. 0 2 0}$ \\
\hline
\end{tabular}

\section{DISCUSSION \& CONCLUSIONS}

The goal of this study was to examine the effects of certain of personal variables on attitudes toward and usage of Web 2.0 applications. Four major findings came out of this investigation: (1) Web 2.0 attitudes had a significant, positive influence on all dimensions of Web 2.0 usage but one, variety of use, (2) there were no differences between males and females in terms of Web 2.0 attitudes, duration of use, and frequency of use but females used more Web 2.0 applications than males do, (3) there were no age or training effects along all usage variables (i.e., duration of use, frequency of use, and variety of use), and (4) age and personal training significantly affected Web 2.0 attitudes. 
Volume XII, No. 1, pp. 483488, 2011

I found that Web 2.0 attitudes had a significant, positive influence on Web 2.0 applications usage frequency and duration. This finding corroborates the findings of previous research in the context of general information technology applications [11]. The result suggests that favorable beliefs about Web 2.0 are important to secure higher Web 2.0 usage. The implication here is that management must find ways to cultivate positive beliefs about Web 2.0. For example, management can encourage trial of Web 2.0 to overcome the psychological fear barrier of the users.

User gender (coded as male $=0$ and female $=1$ ) was found to directly affect variety of use. More specifically, male users were found to use more Web 2.0 applications than female users. This finding is consistent with the findings of past research in the context of end-user computing [2]. A likely reason for this finding may be that male users in our sample place more importance to Web 2.0 tools to do a variety of tasks than females. Gender was also found to affect neither beliefs nor Web 2.0 usage frequency and duration. This result contradicts the findings of previous research [16]. In our sample, male and females users reported similar beliefs and Web 2.0 usage patterns. We further tested the differences between males and females along the three variables using a series of $\mathrm{t}$-tests and found support for the similarity assertion. We remind the reader that our sample was drawn from a pool of users from one organizational level, i.e., professional workers. Therefore, we speculate that our finding may suggest that gender differences along these three variables (Web 2.0 attitudes, duration of use, and frequency of use) that have been reported by some information systems scholars in previous research may partially be attributed to other factors such as organizational level of the respondent.

Age and personal training were found to influence only Web 2.0 attitudes. The younger the user is and the more personal training (s)he receives, the more likely (s)he develop positive Web 2.0 attitudes. However, age and training were not found to affect frequency of use, duration of use, nor variety of use. These findings contradict the results of past research $[2,20]$. Taking the aforementioned results together, one can speculate that age and training affect Web 2.0 usage indirectly through Web 2.0 attitudes.

Admittedly, the present investigation has a few limitations. In this investigation, the tested research model included four determinants of Web 2.0 usage-- age, gender, training, and attitudes toward Web 2.0 applications. In future research, we suggest that other variables such as perceived self-efficacy, ease of use, and usefulness be included and examined. In addition, future research may need to examine the role of IT planning effectiveness [3] in infusing Web 2.0 applications into the work environment of the studied organizations. Last but not least, having a multi-item scale to measure a latent variable is important for sound measurement of variables, therefore, in future studies, there is a need to reconsider the training scale to incorporate multiple items.

\section{REFERENCES}

1. Aladwani, A. M., "Attitudes toward and acceptance of Internet in Kuwait," Global Information Technology Management Association Conference, Memphis, TN, June 11-13, 2000 of Conference.

2. $\quad$ Aladwani, A. M., "End-user computing usage by Kuwaiti managers: The role of individual characteristics," Journal of the Gulf and Arabian Peninsula Studies (27:100), 2001, pp. 17-37.

3. Aladwani, A. M., "IT planning effectiveness in a developing country," Journal of Global Information Technology Management (4:3), 2001 ,pp. 51-65.

4. Aladwani, A. M., "Online banking: A field study of drivers, development challenges, and expectations," International Journal of Information Management (21:3), 2001, pp. 213-225.

5. $\quad$ Aladwani, A. M., "What leads individuals in developing countries to adopt e-banking?," 4th International Conference on Electronic Commerce Research, Dallas, TX, November 8-11, 2001 of Conference.

6. Aladwani, A. M., "Organizational actions, computer attitudes, and end-user satisfaction in public organizations: An empirical study," Journal of End User Computing (14:1), 2002, pp. 42-49.

7. Aladwani, A. M., "A deeper look at the attitude-behavior consistency assumption in information systems satisfaction research," Journal of Computer Information Systems (44:1), 2003 ,pp. 57-63.

8. Aladwani, A. M., "An empirical investigation of electronic shopping in Kuwait," Journal of the Gulf and Arabian Peninsula Studies (29:109), 2003, pp. 43-49.

9. Aladwani, A. M., "An empirical test of the link between web site quality and forward enterprise integration with web consumers," Business Process Management Journal (12:2), 2006, pp. 178-190. 
Volume XII, No. 1, pp. 483488, 2011

10. Cheney, P. H., Mann, R. and Amoroso, D. L., "Organizational factors affecting the success of end-user computing," Journal of Management Information Systems (3:1), 1986, pp. 65-80.

11. Davis, F. D., "Perceived usefulness, perceived ease of use, and user acceptance of information technology," MIS Quarterly (13:3), 1989, pp. 319-340.

12. Delone, W. H., "Determinants of success for computer usage in small business," MIS Quarterly (12:1), 1988, pp. 51-61.

13. Dickson, G., Senn, J. and Chervany, N., "Research in management information systems: The Minnesota experiments," Management Science (23:9), 1977, pp. 913-923.

14. Gefen, D. and Straub, D. W., "Gender differences in the perception and use of E-mail: An extension to the technology acceptance model," MIS Quarterly (21:4), 1997, pp. 389-400.

15. Goodhue, D. L., "IS attitudes: Toward theoretical and definition clarity," Database for Advances in Information Systems (19:3-4), 1988, pp. 6-15.

16. Guimaraes, T and Igbaria, M., "Assessing user computing effectiveness: An integrated model," Journal of End User Computing (9:2), 1997, pp. 3-14.

17. Igbaria, M., "User acceptance of microcomputer technology: An empirical test," Omega (21:1), 1993, pp. 73-90.

18. Igbaria, M. and Chakrabarti, A., "Computer anxiety and attitudes towards microcomputer use," Behaviour \& Information Technology (9:3), 1990, pp. 229-241.

19. Igbaria, M. and Parasuraman, S., "A path analytic study of indivdiual characteristics, computer anxiety and attitudes toward microcomputers," Journal of Management (15:3), 1989, pp. 373-388.

20. Igbaria, M., Pavri, F. N. and Huff, S. L., "Microcomputer Applications: An Empirical Look at Usage," Information \& Management (16:4), 1989, pp. 187-196.

21. Kim, E. and Lee, J., "An Exploratory Contingency Model of User Participation and MIS Use," Information \& Management (11:2), 1986, pp. 87-97.

22. Legris, P., Ingham, J. and Collerette, P., "Why do people use information technology? A critical review of the technology acceptance model," Information \& Management (40:3), 2003, pp. 191-204.

23. Magnuson, J., Dundes, M., \& Dundes, L. "Gender Differences in Social Portraits' Reflected in MySpace Profiles," CyberPsychology \& Behavior (11:2), 2008, pp. 239 - 241.

24. Pfeil, U., Arjan, R., \& Zaphiris, P. "Age differences in online social networking - A study of user profiles and the social capital divide among teenagers and older users in MySpace," Computers in Human Behavior (25:3), 2009, pp. 643-654.

25. Rajeev, S., \& Philip, Y. "The Contingent Effects of Training, Technical Complexity, and Task Interdependence on Successful Information Systems Implementation,” MIS Quarterly (31:2), 2007, pp. 219-243.

26. Venkatesh, V., Morris, M., Davis, G. and Davis, F., " User acceptance of information technology: Toward a unified view," MIS Quarterly (27:3), 2003, pp. 425-478.

27. Zmud, R. W., "Individual differences and MIS success: A review of the empirical literature," Management Science (25:10), 1979, pp. 966-979. 